\title{
A preponderance of small dense LDL is associated with specific insulin, proinsulin and the components of the insulin resistance syndrome in non-diabetic subjects
}

\author{
S.M. Haffner ${ }^{1}$, L. Mykkänen ${ }^{1}$, D. Robbins ${ }^{2}$, R. Valdez ${ }^{1}$, H. Miettinen ${ }^{1}$, B. V. Howard ${ }^{2}$, M. P. Stern ${ }^{1}$, R. Bowsher ${ }^{3}$ \\ ${ }^{1}$ Division of Clinical Epidemiology, Department of Medicine, University of Texas Health Science Center at San Antonio, \\ San Antonio, Texas, USA \\ ${ }^{2}$ Medlantic Research Institute, Washington, D. C., USA \\ ${ }^{3}$ Lilly Laboratories, University of Indiana, Indianapolis, Indiana, USA
}

Summary Recently, the presence of small dense low density lipoprotein (LDL) has been postulated to be a stronger risk factor for coronary heart disease than large LDL. While small dense LDL has been associated with individual components of the insulin resistance syndrome such as hypertension, high triglyceride level, low high density (HDL) cholesterol, and diabetes mellitus, there has been little work exploring whether LDL size is decreased in subjects with multiple metabolic disorders. We examined the association of LDL size and pattern to specific insulin (which does not cross-react with proinsulin), proinsulin, increased triglyceride, decreased HDL, hypertension and impaired glucose tolerance in 488 non-diabetic subjects from the San Antonio Heart Study. LDL size was significantly related to specific insulin, proinsulin and the fasting proinsulin/insulin ratio. Small dense LDL was significantly associated with high triglyceride level, decreased HDL cholesterol, hypertension and impaired glucose tolerance. LDL size (̊) decreased in a stepwise fashion with increasing number of the metabolic disorders described above (zero $262.6 \pm 9.4$; one $257.0 \pm 9.3$; two $256.4 \pm 9.4$; three $249.0 \pm 9.1$; and four $244.9 \pm 9.0$ ). These results were similar in men and women and in non-Hispanic whites and Mexican Americans. The association between LDL size and the number of metabolic disorders remained statistically significant even after adjustment for obesity, body fat distribution, gender, ethnicity, proinsulin and insulin concentrations. Furthermore, decreases in LDL size are also significantly associated with both a selective beta-cell defect (as estimated by the fasting proinsulin/insulin ratio) and insulin resistance (as estimated by the fasting insulin concentrations) although the association was somewhat stronger for the latter. We conclude that small dense LDL may form part of the insulin resistance syndrome in non-diabetic subjects. [Diabetologia (1995) 38: 1328-1336]

Key words Insulin resistance syndrome, low density lipoprotein size, triglyceride, high-density lipoprotein, hypertension.
Increased concentration of low density lipoprotein (LDL) cholesterol is widely recognized as a risk factor for coronary heart disease $[1,2]$. There is consid-

Received: 22 March 1995 and in revised form: 9 May 1995

Corresponding author: Dr. S. M. Haffner, University of Texas Health Science Center at San Antonio, Department of Medicine, Division of Clinical Epidemiology, 7703 Floyd Curl Drive, San Antonio, TX 78284-7873, USA

Abbreviations: BMI, Body mass index; LDL, low density lipoprotein; HDL, high density lipoprotein; IGT, impaired glucose tolerance; NIDDM, non-insulin-dependent diabetes mellitus; WHR, waist-hip ratio. erable heterogeneity in the size and density of LDL particles [3, 4]. Austin et al. found that most individuals can be assigned to one of two LDL subclass patterns (A or B) [5]. Small dense LDL particles (pattern B) are thought to be more atherogenic than larger LDL particles, although this association may not be statistically independent of triglyceride concentrations [5-7].

Recently, several clinical and epidemiological studies have shown an association between insulin concentrations and various metabolic and physiologic abnormalities including glucose intolerance, dyslipidaemia (specifically, increased triglyceride lev- 
el and decreased high density lipoprotein (HDL) cholesterol) and hypertension [8-11]. These disorders are also associated with insulin resistance [12-16]. In two prospective studies, several metabolic disorders related to the insulin resistance syndrome have been found to cluster together $[17,18]$.

Small dense LDL has been associated with most individual components of the insulin resistance syndrome including hypertriglyceridaemia [4-7, 19-22], low HDL cholesterol [5, 19-22], hypertension [20, $21,23]$, diabetes $[20,22,24,25]$ and hyperinsulinaemia and insulin resistance [19-22]. Few data, however, are available on whether small dense LDL is a characteristic of the cluster of risk factors associated with insulin resistance. Selby et al. [20] have shown that women with multiple metabolic disorders are more likely to have small dense LDL than women with a single disorder.

Many of the studies describing the association of insulin resistance and/or hyperinsulinaemia to cardiovascular risk factors have been limited by the fact that insulin was measured with an assay that cross-reacts with proinsulin. Temple et al. [26] have suggested that proinsulin and split 32-33 proinsulin comprise the majority of circulating immunoreactive insulin in subjects with NIDDM. Several other studies have also suggested that proinsulin is elevated disproportionately in subjects with NIDDM [27-33]. Both proinsulin and insulin are also elevated in subjects with impaired glucose tolerance (IGT) [30, 33, 34]. However, the results on the ratio of proinsulin to insulin in subjects with IGT have been contradictory. In one study, the ratio of proinsulin to insulin was not elevated [31], whereas in another report the proinsulin/ insulin ratio was increased [34]. Proinsulin concentrations are correlated with dyslipidaemia and hypertension in diabetic [35] and non-diabetic subjects [36]. However, it is not known whether proinsulin concentrations, specific insulin concentrations or both are associated with alterations in LDL size.

We have examined for the first time the association between proinsulin, specific insulin (using an antibody that does not cross-react with proinsulin) and the fasting proinsulin/insulin ratio to LDL size. In this report, we also examine the association of LDL size and pattern to a number of metabolic disorders (hypertension, low HDL, hypertriglyceridaemia and impaired glucose tolerance) identified in prospective studies of the insulin resistance syndrome $[17,18]$ in men and women from a biethnic population. In previous studies, subjects who have multiple metabolic disorders have higher insulin concentrations [17] and are more insulin resistant [37] than subjects who develop only a single disorder. Since age, obesity and body fat distribution are associated with both insulin resistance and LDL size [20,21] we also adjusted for these possible confounding variables. Since diabetes has been associated with a preponderance of small dense
LDL in a number of reports $[20,22,24,25]$ including our own population [24] we have examined these associations in non-diabetic subjects.

\section{Subjects and methods}

The San Antonio Heart Study is a population-based study of diabetes and cardiovascular disease in Mexican Americans and non-Hispanic whites. Mexican Americans were defined as individuals whose ancestry and cultural traditions derived from a Mexican national origin [38]. Detailed descriptions of the 1979-1982 survey (phase I) and the 1984-1988 survey (phase II) as well as the 8-year follow-up have been previously published [39-41]. This study was approved by the Institutional Review Board for the University of Texas Health Science Center at San Antonio. All subjects gave informed consent. The results presented in this study are based on the first two (out of six) census tracts in the 7-year follow-up of the phase II cohort, which began in October 1990.

At the follow-up examination, blood specimens were obtained following a 12-14 h fast, and a second specimen was obtained $2 \mathrm{~h}$ after administration of a $75 \mathrm{-g}$ glucose equivalent load (Orangedex, Custom Laboratories, Baltimore, Md., USA). Plasma glucose concentrations were measured with an Abbott VIP Analyzer (Abbott Laboratories, North Chicago, IIl., USA). For subjects included in the present report we measured serum insulin concentrations by a commercial double antibody radioimmunoassay (RIA) (human insulin-specific RIA method, LINCO Research, St. Louis, Mo., USA) in which proinsulin cross-reactivity is less than $0.2 \%$. The lower limit of sensitivity of the Linco assay was $14.4 \mathrm{pmol} / \mathrm{l}$. The intra-assay coefficient of variation was $4.5 \%$ and the interassay coefficient of variation was less than $10 \%$ [42]. Proinsulin concentrations were measured in the laboratory of Dr. R. Bowsher (Lilly Laboratory for Clinical Research, Indianapolis, Ind, USA) by a nonequilibrium RIA method [36]. The polyclonal antibody used in this assay (168AB) recognizes a proinsulin-specific epitope formed by the intact A-chain-C-peptide junction. Fasting lipids and lipoproteins were measured using methods described previously [39]. The intra-assay coefficient of variation ranged from 6 to $21 \%$ using controls prepared at 5,50 and 250 $\mathrm{pmol} / \mathrm{l}$.

Diabetes mellitus was diagnosed according to the criteria of the World Health Organization (WHO) (fasting plasma glucose $\geq 7.8 \mathrm{mmol} / 1(140 \mathrm{mg} / \mathrm{dl})$ and/or 2 -h plasma glucose value $\geq 11.1 \mathrm{mmol} / \mathrm{l}(200 \mathrm{mg} / \mathrm{dl}))$ [43]. Subjects who did not meet these criteria but who were being treated with oral anti-diabetic agents or insulin were also considered to have diabetes. Impaired glucose tolerance was also diagnosed according to WHO criteria (fasting plasma glucose $<7.8 \mathrm{mmol} / 1(140 \mathrm{mg} /$ dl) and 2-h plasma glucose between $7.8 \mathrm{mmol} / 1$ (140 mg/dl) and $11.1 \mathrm{mmol} / 1(200 \mathrm{mg} / \mathrm{dl})$ ) [42]. Since the focus of this report is on the insulin resistance syndrome in non-diabetic subjects and since LDL size is related to diabetes $[20,22,24,25]$ we excluded the 125 subjects with diabetes.

Anthropometric measurements (height, weight, waist and hip circumferences) were obtained after participants had removed their shoes and upper garments and donned an examining gown [44]. Body mass index (BMI) was calculated as weight $(\mathrm{kg})$ divided by height $(\mathrm{m})$ squared. The ratio of waistto-bip circumference (WHR) was used as a measure of body fat distribution.

Systolic blood pressure (first phase) and diastolic blood pressure (fifth phase) were measured to the nearest even digit with a random zero sphygmomanometer (Hawksley-Gelman, 
Lancing, Sussex, UK) [45]. Hypertension was defined as a systolic blood pressure greater or equal than $140 \mathrm{mmHg}$ and/or a diastolic blood pressure greater or equal than $90 \mathrm{mmHg}$ and $/$ or current use of antihypertensive medication which corresponds to the mild hypertension category of the Joint National Committee on Detection, Education and Treatment of High Blood Pressure (JNC V) recommendations [46].

LDL size and subclass pattern were determined in plasma samples by the method of Krauss and Burke [4] in the laboratory of the Medlantic Research Institute, Washington, D. C., USA. Plasma samples for determination of LDL size were stored at $-70^{\circ} \mathrm{C}$ (without thawing) until the analyses for $\mathrm{LDL}$ size were done, an average of 3 months later. Gradient gels were obtained from Isolab, Inc. (Akron, Ohio, USA). Measurement of the particle sizes was calibrated using LDL subfractions whose molecular diameter had been determined by analytical ultracentrifugation (courtesy of Dr. R. Krauss, Donner Laboratories, Berkeley, Calif., USA). In almost all subjects, a predominant LDL peak could be determined. The size of the predominant peak was considered the individuals' LDL size. Subjects were classified into three groups on the basis of size and shape of the major peak. A major gradient peak of greater than $257 \AA$ with skewing toward smaller particles was classified as pattern A. Individuals with a predominant peak of less than $253.5 \AA$ were classified as pattern $B$ and those subjects between 253.5 and $257 \AA$, were classified as pattern I unless the size was very close to the cutpoints and the peak had the characteristic shape of either the A or B pattern. The mean sizes in $(\AA)$ of the $A, I$ and B peaks were $264.7 \pm 0.3$, $255.3 \pm 0.4$, and $244.5 \pm 0.4$, respectively. The interassay coefficient of variation for eight control pools $(240-263 \AA)$ ranged from 1.8 to $3.6 \%$ [19].

On the basis of previous prospective epidemiologic studies $[17,18]$, we considered four metabolic conditions to be most closely associated with the insulin resistance syndrome: IGT; hypertension; low HDL cholesterol; and high triglyceride concentrations. Triglyceride concentrations were dichotomized as above or below $2.3 \mathrm{mmol} / \mathrm{l}(200 \mathrm{mg} / \mathrm{dl})$ as recently recommended by the National Cholesterol Education Program (NCEP) [47]. Also as recommended by the NCEP, HDLC was dichotomized as above or below $0.9 \mathrm{mmol} / 1(35 \mathrm{mg} / \mathrm{dl})$ for men. For women, we used a higher cutoff-point $1.2 \mathrm{mmol} / \mathrm{l}$ $(45 \mathrm{mg} / \mathrm{d} \mathrm{l})$ than recommended by the NCEP to increase the number of abnormal values. We used the WHO criteria [43] for the diagnosis of impaired glucose tolerance and the mild hypertension definition of the JNC V [45] as noted.

\section{Statistical analyses}

Statistical techniques included Spearman correlation coefficients, partial correlation efficients, parametric analyses of variance, multiple linear regression, multiple logistic regression and chi-squared tests. We confirmed that the distribution of LDL size of the predominant peak was normally distributed using normal probability plots. The skewness of the LDL size distribution was -0.16 and the kurtosis was -0.71 also suggesting an approximately normal distribution. Triglyceride concentrations were logarithmically transformed to reduce skewness and kurtosis. Statistical analyses were performed on the natural logarithms and the results were back-transformed into their natural units for presentation in the Tables. Interactions between ethnicity (or sex) and other variables (number of metabolic disorders, LDL size, insulin, etc.) were examined using both logistic regression and analyses of variance. There were no statistically significant interactions $(p>0.20)$. Therefore, the ethnic groups and both sexes were pooled in most analyses for greater statistical power and ease of presentation.

\section{Results}

Table 1 shows the anthropometric, metabolic and haemodynamic characteristics of non-diabetic subjects by gender. The mean LDL size in women is $258.3 \pm 0.6 \AA$ and in men is $256.0 \pm 0.7 \AA$ $(p=0.029)$.

Table 2 shows Pearson correlations between LDL size, insulin, proinsulin and cardiovascular risk factors. LDL size was significantly positively correlated with HDL cholesterol and inversely correlated with insulin, proinsulin, the fasting proinsulin/insulin ratio, triglyceride, total and LDL cholesterol, blood pressure and glucose levels. Insulin, proinsulin and the proinsulin/insulin ratio were also, in general, correlated with cardiovascular risk factors.

Table 3 shows partial correlation coefficients after adjustment for age, gender, BMI, WHR, glucose, triglyceride, and HDL cholesterol. Insulin, proinsulin and the fasting proinsulin/insulin ratio were all significantly inversely correlated with LDL size after adjustment for possible confounding variables.

We also considered whether the fasting proinsulin/ insulin ratio (as a marker of selective beta-cell secondary failure) predicts LDL size independently of fasting insulin concentrations (as a marker of insulin resistance). To examine this issue we stratified nondiabetic subjects by both the median level of fasting insulin $(110.2 \mathrm{pmol} / \mathrm{l})$ and the fasting proinsulin/insulin ratio (0.075) (Fig. 1). Both fasting insulin concentrations $(r=0.002)$ and the fasting proinsulin/insulin ratio $(p=0.008)$ were inversely significantly related to LDL size but the association was stronger for fasting insulin. LDL size was lowest in hyperinsulinaemic subjects with a high fasting proinsulin/insulin ratio.

Figures 2 and 3 show LDL size and patterns by four selected metabolic disorders. Smaller, denser LDL was significantly related to increased triglyceride $(p<0.001)$, decreased HDL cholesterol $(p<$ $0.001)$, hypertension $(p=0.031)$ and IGT $(p=0.048)$.

We next examined the association of the number of metabolic disorders to LDL size separately in men and women and also in Mexican Americans and non-Hispanic whites. LDL size was significantly related to the number of metabolic disorders after stratification by gender or ethnicity (data not shown). These results were similar in Mexican Americans and non-Hispanic whites separately, and in men and women separately. The gender $\times$ number of metabolic disorders and the ethnicity $\times$ number of metabolic disorder interaction terms were not statistically significant ( $p=0.900$ and $p=0.451$, respectively). We therefore combined the sexes and ethnic groups 
Table 1. Anthropometric, metabolic and haemodynamic characteristics by gender in non-diabetic subjects

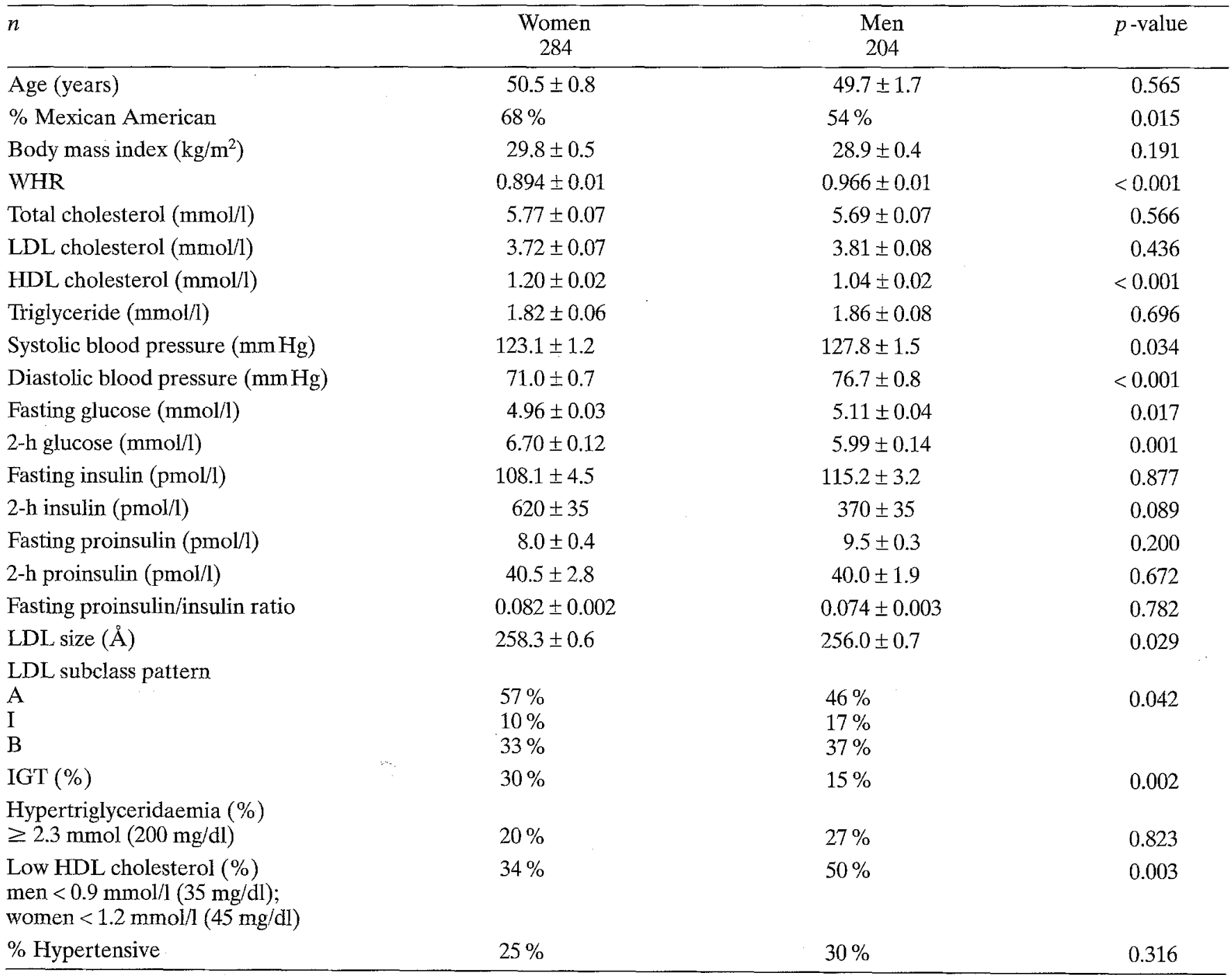

Data are mean \pm SEM

$(n=488$ subjects $)$

in subsequent analyses to simplify the presentation and improve statistical power.

Figure 4 shows LDL size and proportion of pattern $B$ by the number of metabolic disorders. LDL size decreased and the proportion of pattern $B$ increased significantly with increasing number of metabolic disorders.

Table 4 shows the relationship stratified by the level of each metabolic disorder of LDL size to the number of remaining metabolic disorders (zero to three). In these analyses, LDL size remains significantly associated with the number of metabolic disorders even after stratification for high or low levels of triglyceride, HDL, IGT or hypertension.

Since age, obesity and body fat distribution may also be related to both LDL size and the number of metabolic disorders, we controlled for the effect of these possible confounding variables by multiple linear regression in non-diabetic subjects. In these analy- ses, LDL size is the dependent variable. The number of metabolic disorders continued to be significantly related to LDL size even after adjustment for age, obesity, body fat distribution, gender and ethnicity (data not shown). For example, each additional metabolic disorder was associated with a $4.7 \AA$ decrease in LDL size. Fasting insulin, the fasting proinsulin/insulin ratio and gender also predicted LDL size. When we repeated these analyses using multiple logistic regression models in which the presence of LDL subclass pattern $B$ was the dependent variable we obtained very similar results (data not shown).

\section{Discussion}

We have previously shown that in a smaller number of diabetic and non-diabetic subjects immunoreactive insulin concentrations are associated with a pre- 
Table 2. Pearson correlation of LDL size with insulin and proinsulin and metabolic variables

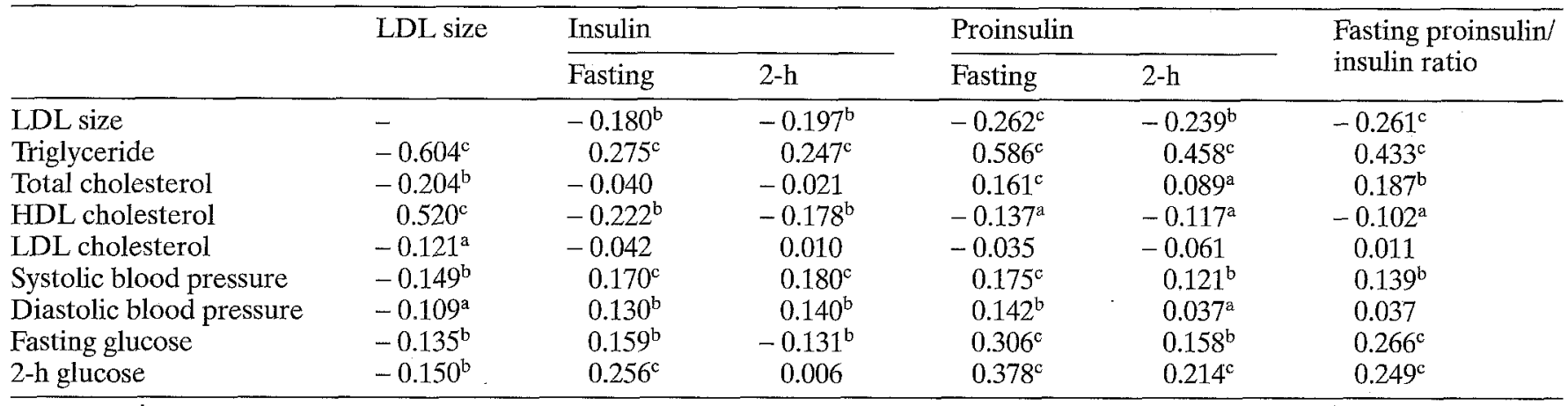

${ }^{\mathrm{a}} p<0.05 ;{ }^{\mathrm{b}} p 0.01 ;{ }^{\mathrm{c}} p<0.001(n=488$ subjects $)$

Table 3. Partial correlation coefficients of LDL size with insulin and proinsulin

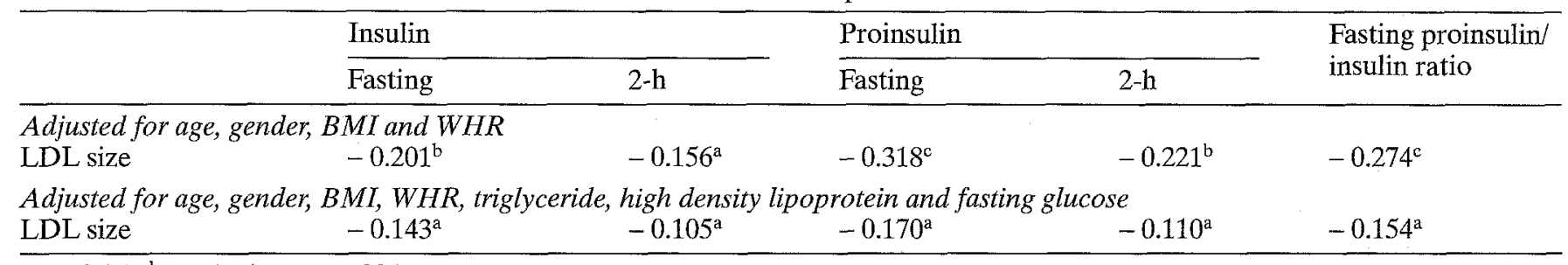

${ }^{\mathrm{a}} p<0.05 ;{ }^{\mathrm{b}} p<0.01 ;{ }^{\mathrm{c}} p<0.004$

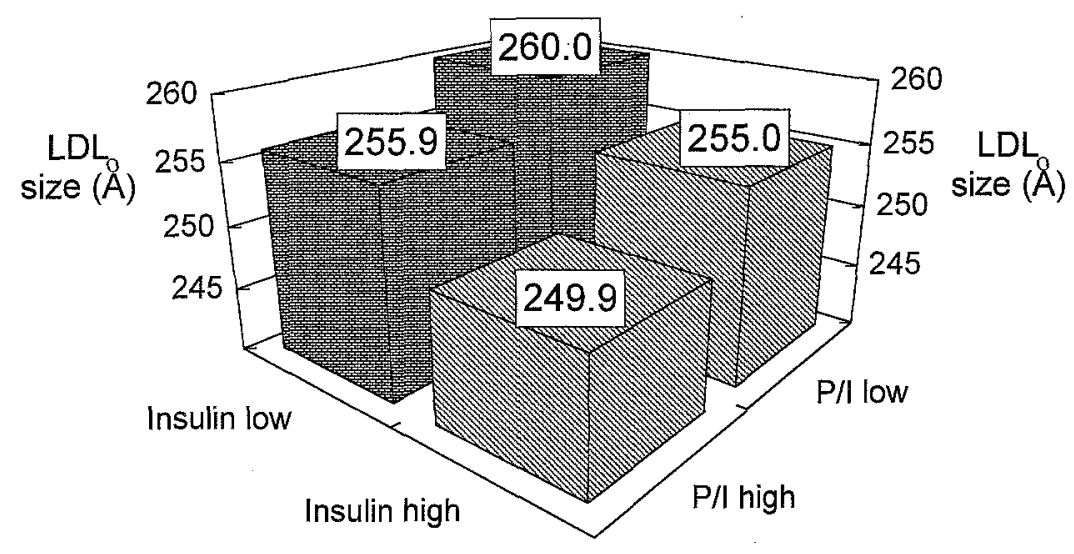

Fig. 1. LDL size by fasting insulin (I) and the fasting proinsulin/insulin (P/I) ratio in non-diabetic subjects. $p$-values calculated by two-way analysis of variance (insulin $p=0.002$; proinsulin $p=0.008$ ) ponderance of smaller denser LDL particles [19]. We have now shown for the first time that LDL size is inversely associated with both specific insulin and proinsulin concentrations and the proinsulin/insulin ratio. This suggests that a more atherogenic LDL pattern may occur not only with insulin resistance but also in subjects with abnormal insulin secretion. However, the effect of insulin resistance (as estimated by fasting insulin concentrations) was somewhat stronger than the effect of abnormal beta-cell function (as judged by the fasting proinsulin/insulin ratio on LDL size (Fig. 1). We have previously shown that increased proinsulin and specific insulin concentrations are associated with increased blood pressure, and increased triglyceride levels in a smaller number of subjects [36]. Furthermore, the fasting proinsulin/insulin ratio was associated with an in- creased number of metabolic disorders in non-diabetic subjects [48].

We have shown in this report that small dense LDL, whether measured as LDL size, a continuous variable, or as the dichotomous B vs A LDL subclass pattern, is associated with multiple metabolic disorders. These associations were not dependent on obesity or on unfavourable body fat distribution, both of which exist in insulin-resistant subjects; furthermore, similar relations between LDL size and insulin resistance syndrome-related disorders occur in both men and women and in Mexican Americans and non-Hispanic whites. Our results confirm earlier work by Selby et al. [20] in the Kaiser Permanente Women Twins Study. In the current report as in a previous report [19], insulin concentrations were associated with LDL size. However, the number of metabolic disor- 


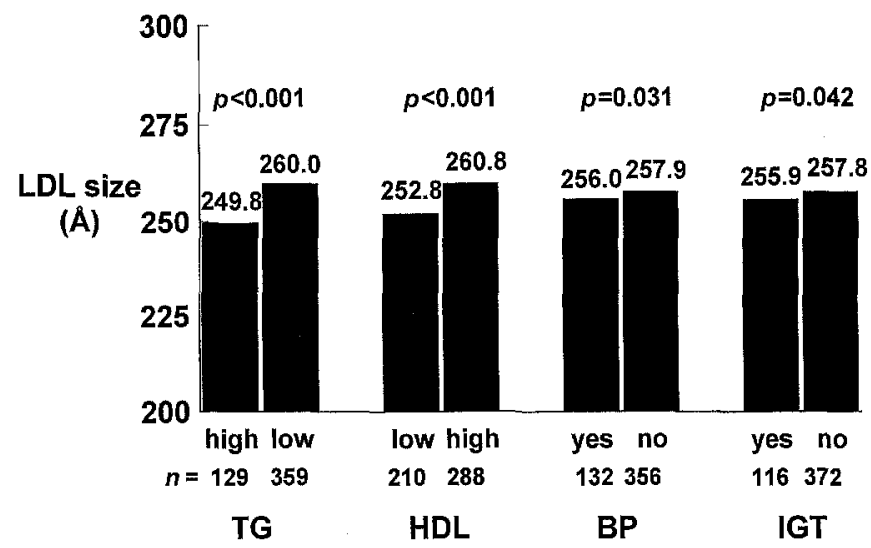

Fig. 2. LDL size by: triglyceride; HDL cholesterol; blood pressure; and impaired glucose tolerance in non-diabetic subjects

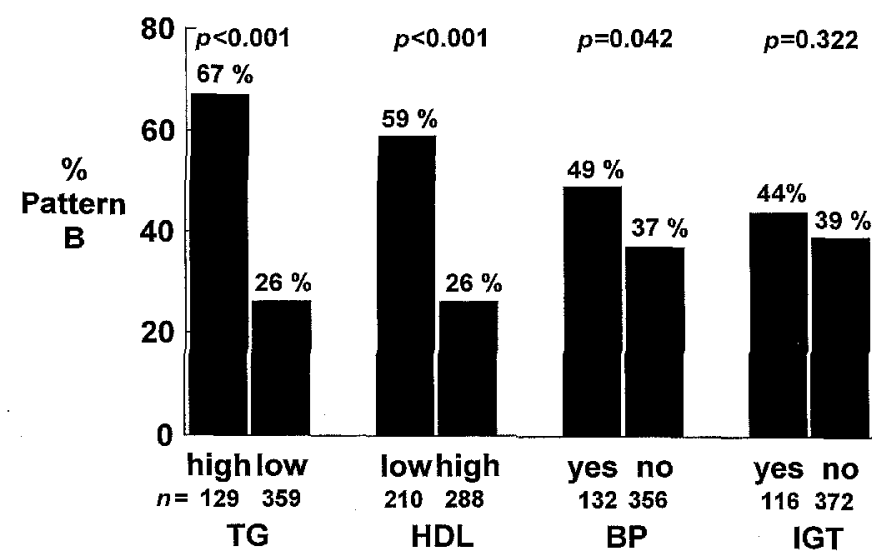

Fig. 3. The percent LDL subclass pattern B by: triglyceride; HDL cholesterol; blood pressure; and impaired glucose tolerance in non-diabetic subjects

ders was significantly related to LDL size even after controlling for insulin concentrations. Since the correlation between fasting insulin concentrations and insulin resistance is only moderate $(r=-0.6)[49,50]$, it is possible that controlling for insulin resistance directly might statistically account for the entire association between the insulin resistance syndrome and LDL size.

In this report, as in previous studies, LDL size was lower in subjects with higher triglyceride [4-7, 1922] and low HDL cholesterol concentrations [5, 1922]. Subjects with hypertriglyceridaemia and decreased HDL cholesterol also had a significantly higher prevalence of LDL subclass B.

Subjects with hypertension also had significantly smaller LDL size and a higher prevalence of LDL subclass pattern $B$ than normotensive subjects. Selby et al. [20] found a significant association between hypertension and LDL subclass pattern $B$, but not LDL size. LDL size has also been found to be reduced in subjects with familial dyslipidaemic hypertension [51] and in subjects taking beta blockers [23]. Exclusion of the subjects on pharmacological therapy

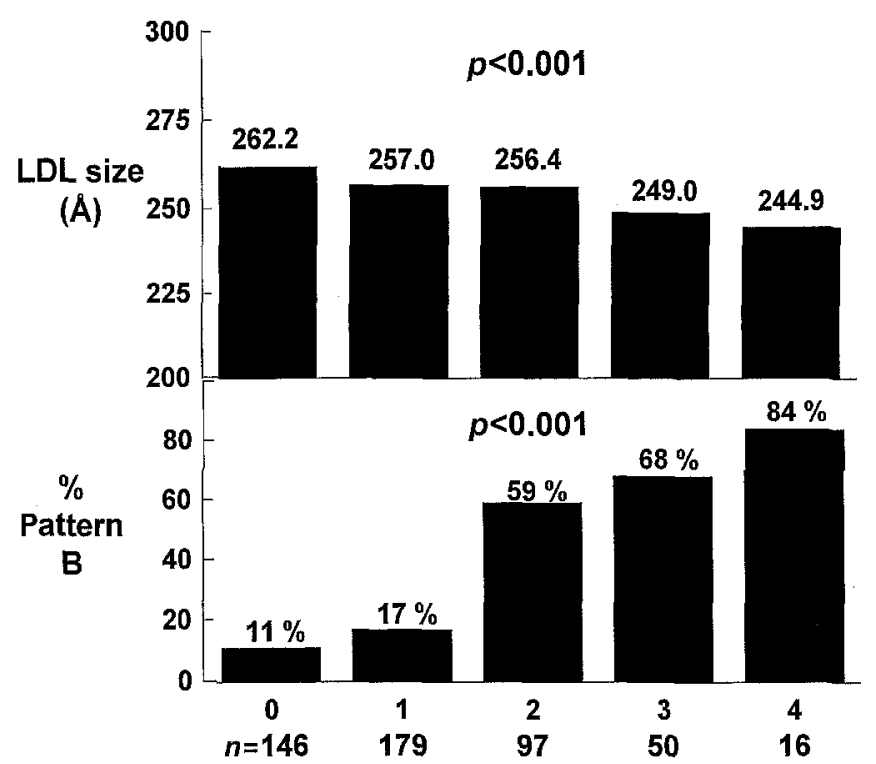

Fig. 4. LDL size and subclass pattern by the number of metabolic disorders in non-diabetic subjects

for hypertension did not affect the association between LDL size and the number of metabolic disorders (data not shown). In the current report, the association between hypertension and LDL size or pattern was not statistically significant after adjusting for the number of other metabolic disorders. This suggests that the smaller denser LDL observed in the current report is most likely due to the higher triglyceride and lower HDL cholesterol observed in hypertensive subjects.

Although a number of studies has shown that subjects with NIDDM have smaller denser LDL than non-diabetic subjects $[20,22,24,25]$, few data are available on the effect of IGT on LDL size. In the current report, we observed smaller LDL size in subjects with IGT compared to subjects with normal glucose tolerance (Fig.2). Selby et al. [20] have shown that in women with IGT LDL size was intermediate between those with normal glucose tolerance and diabetes. Recently, Austin et al. [52] have shown a preponderance of small dense LDL prior to the onset of NIDDM in elderly Finnish subjects.

The associations of LDL size with hypertriglyceridaemia and low HDL cholesterol was much stronger than its association with hypertension or IGT. However, the association between LDL size and the number of multiple metabolic disorders was not only dependent on the triglyceride and HDL concentrations. LDL size significantly decreased in a stepwise fashion with the increasing number of metabolic disorders (Fig.4). Thus, the impact of having three or four metabolic defects on LDL composition was larger than having only two disorders (most likely to be high triglyceride level and low HDL cholesterol).

Subjects with the insulin resistance syndrome have higher triglyceride and lower HDL cholesterol levels 
Table 4. LDL size and the proportion of pattern $\mathrm{B}^{\mathrm{a}}$ according to the number of metabolic disorders stratified by levels of selected metabolic disorders in non-diabetic subjects

\begin{tabular}{|c|c|c|c|c|c|c|}
\hline & \multicolumn{4}{|c|}{ Number of metabolic disorders } & \multicolumn{2}{|c|}{$p$-value } \\
\hline & 0 & 1 & 2 & 3 & & \\
\hline $\begin{array}{l}\text { Triglyceride } \\
\text { high }(n=129) \\
(\% \text { pattern B }) * \\
\text { low }(n=359) \\
(\% \text { pattern B }) *\end{array}$ & $\begin{array}{l}254.4 \\
(65 \%) \\
262.6 \\
(16 \%)\end{array}$ & $\begin{array}{l}249.6 \\
(79 \%) \\
257.5 \\
(39 \%)\end{array}$ & $\begin{array}{l}248.5 \\
(85 \%) \\
260.9 \\
(54 \%)\end{array}$ & $\begin{array}{l}244.9 \\
(89 \%) \\
252.7 \\
(67 \%)\end{array}$ & $\begin{array}{l}\text { TG } \\
<0.001 \\
(<0.001)\end{array}$ & $\begin{array}{l}\text { NOMD } \\
<0.001 \\
(0.002)\end{array}$ \\
\hline $\begin{array}{l}\text { HDL cholesterol } \\
\text { low }(n=210) \\
\text { (\% pattern B)* } \\
\text { high }(n=288) \\
(\% \text { pattern } B)^{*}\end{array}$ & $\begin{array}{l}255.1 \\
(51 \%) \\
262.6 \\
(16 \%)\end{array}$ & $\begin{array}{l}254.9 \\
(45 \%) \\
260.5 \\
(38 \%)\end{array}$ & $\begin{array}{l}248.1 \\
(75 \%) \\
258.9 \\
(58 \%)\end{array}$ & $\begin{array}{l}244.9 \\
(89 \%) \\
254.4 \\
(60 \%)\end{array}$ & $\begin{array}{l}\text { HDL } \\
\quad<0.001 \\
(<0.001)\end{array}$ & $\begin{array}{l}\text { NOMD } \\
<0.001 \\
(<0.002)\end{array}$ \\
\hline $\begin{array}{l}\text { Hypertension } \\
\text { yes }(n=132) \\
(\% \text { pattern } \mathrm{B}) * \\
\text { no }(n=356) \\
(\% \text { pattern } \mathrm{B}) *\end{array}$ & $\begin{array}{l}258.3 \\
(16 \%) \\
262.6 \\
(16 \%)\end{array}$ & $\begin{array}{l}256.5 \\
(36 \%) \\
256.6 \\
(46 \%)\end{array}$ & $\begin{array}{l}250.0 \\
(80 \%) \\
252.7 \\
(65 \%)\end{array}$ & $\begin{array}{l}244.9 \\
(80 \%) \\
247.1 \\
(86 \%)\end{array}$ & $\begin{array}{c}\uparrow \mathrm{BP} \\
0.444 \\
(0.872)\end{array}$ & $\begin{array}{l}\text { NOMD } \\
<0.001 \\
(<0.001)\end{array}$ \\
\hline $\begin{array}{l}I G T \\
\text { yes }(n=110) \\
(\% \text { pattern } \mathrm{B})^{*} \\
\text { no }(n=372) \\
(\% \text { pattern } \mathrm{B})^{*}\end{array}$ & $\begin{array}{l}261.8 \\
(21 \%) \\
263.5 \\
(16 \%)\end{array}$ & $\begin{array}{l}258.4 \\
(46 \%) \\
255.9 \\
(36 \%)\end{array}$ & $\begin{array}{l}247.6 \\
(79 \%) \\
253.4 \\
(59 \%)\end{array}$ & $\begin{array}{l}244.9 \\
(89 \%) \\
247.8 \\
(60 \%)\end{array}$ & $\begin{array}{l}\text { IGT } \\
0.182 \\
(0.363)\end{array}$ & $\begin{array}{l}\text { NOMD } \\
<0.001 \\
(<0.001)\end{array}$ \\
\hline
\end{tabular}

Data are mean $\pm \operatorname{SEM}(n=488$ subjects $)$

NOMD, Number of metabolic disorders.

* Subjects with pattern I excluded from these analyses

${ }^{a}$ Maximum number of metabolic disorders is three since one disorder is being stratified

[8-12] which may contribute to increased risk for coronary heart disease. However, they have relatively normal LDL cholesterol levels. We have shown in this report that a preponderance of small dense LDL is also strongly associated with the metabolic disorders which characterize the insulin resistance syndrome, suggesting that small dense LDL may explain part of the increased risk of atherosclerosis in this disorder. Furthermore, decreases in LDL size are also significantly associated with both a selective betacell defect (as estimated by the fasting proinsulin/insulin ratio) and insulin resistance (as estimated by the fasting insulin concentrations) although the association was somewhat stronger for the latter. We conclude that small dense LDL may form part of the insulin resistance syndrome.

Acknowledgements. This work was supported by grants R01 HL24799 and R37 HL36820 from the National Heart, Lung and Blood Institute. Dr. Valdez was supported by the ADA Mentor-based Post Doctoral Fellowship program.

This work was presented in part at the 66th Annual meeting of the American Heart Association, Atlanta, Ga, November 8$11,1993$.

\section{References}

1. Castelli WP, Garrison RJ, Wilson PWF, Abbott RD, Kalousdian S, Kannel W (1986) Incidence of coronary heart disease and lipoprotein cholesterol levels: the Framingham Heart Study. JAMA 256: 2835-2838

2. Kannel W, Castelli WP, Gordon T, McNamara PM (1971) Serum cholesterol, lipoproteins and the risk of coronary heart disease: the Framingham Study. Ann Intern Med 74: $1-12$

3. Shen MMS, Krauss RM, Lindgren FT, Forte TM (1981) Heterogeneity of serum low density lipoproteins in normal human subjects. J Lipid Res 22: 236-244

4. Krauss RM, Burke DJ (1984)Identification of multiple subclasses of plasma low density lipoproteins in normal humans. J Lipid Res 23: 97-104

5. Austin MA, Breslow JL, Hennekens CH, Buring JE, Willett WC, Krauss RM (1988) Low density lipoprotein subclass patterns and risk of myocardial infarction. JAMA 260: 1917-1921

6. Crouse JR, Parks JS, Schey HM, Kahl FT (1985) Studies of low density lipoprotein molecular weight in human beings with coronary artery disease. J Lipid Res 26: 566-574

7. Campos H, Genest JJ, Blijlevens E et al. (1992) Low density lipoprotein particle size and coronary artery disease. Arteriosclerosis 12: 187-195

8. Modan M, Halkin H, Almog S et al. (1985) Hyperinsulinemia: a link between hypertension, obesity and glucose intolerance. J Clin Invest 75: 809-817

9. Zavaroni I, Bonora E, Pagliara M et al. (1989) Risk factors for coronary artery disease in healthy persons with hyperinsulinaemia and normal glucose tolerance. $\mathrm{N}$ Engl J Med 320: $702-706$ 
10. Orchard TJ, Becker DJ, Bates M, Kuller LH, Drash AL (1983) Plasma insulin and lipoprotein concentrations: an atherogenic association? Am $\mathrm{J}$ Epidemiol 118: $326-337$

11. Haffner SM, Fong D, Hazuda HP, Pugh JA, Patterson JK (1988) Hyperinsulinemia, upper body adiposity, and cardiovascular risk factors in non-diabetics. Metabolism 37 : 338-345

12. DeFronzo RA, Ferrannini E (1991) Insulin resistance: a multifaceted syndrome responsible for NIDDM, obesity, hypertension, dyslipidaemia and atherosclerotic cardiovascular disease. Diabetes Care 14: 173-194

13. Ferrannini E, Buzzigoli G, Bonadonna R et al. (1987) Insulin resistance in essential hypertension. $\mathrm{N}$ Engl $\mathbf{J}$ Med 317: 350-357

14. Garg A, Gelderman JH, Koffler M, Ayuso R, Rosenstock J, Raskin P (1988) Relationship between lipoprotein levels and in vivo insulin action in normal white men. Metabolism 37: 982-987

15. Abbott WGH, Lillioja S, Young AA et al. (1987) Relationship between plasma lipoprotein concentrations and insulin concentrations and insulin action in an obese hyperinsulinaemic population. Diabetes 36: 897--904

16. Reaven GM (1988) Banting Lecture 1988. Role of insulin resistance in human disease. 37: 1595-1607

17. Haffner SM, Valdez RA, Hazuda HP, Mitchell BD, Morales PA, Stern MP (1992) Prospective analyses of the insulin resistance syndrome (syndrome $X$ ). Diabetes 41: 715722

18. Mykkänen L, Kuusisto J, Pyörälä K, Laakso M (1993) Cardiovascular risk factors as predictors of type 2 (non-insulin-dependent) diabetes mellitus in elderly subjects. Diabetologia $36: 553-559$

19. Haffner SM, Mykkänen L, Valdez RA, Paidi M, Stern MP, Howard BV (1993) Low density lipoprotein size and subclass pattern in a biethnic population. Arterioscler Thromb 13: $1623-1630$

20. Selby JV, Austin MA, Newman B et al. (1993) LDL subclass pattern and the insulin resistance syndrome in women. Circulation 88: 381-387

21. Reaven GM, Chen YDI, Jeppesen J, Mabeux P, Krauss RM (1993) Insulin resistance and hyperinsulinaemia in individuals with small dense low density lipoprotein particles. J Clin Invest 92: 141-146

22. Barakat HA, Carpenter JW, McLendon VD et al. (1990) Influence of obesity, impaired glucose tolerance, and NIDDM on LDL structure and composition. Possible link between hyperinsulinaemia and atherosclerosis. Diabetes 39: $1527-1533$

23. Schaefer EJ, McNamara JR, Genest J et al. (1987) LDL particle size, lipoproteins and apolipoproteins in premature coronary disease: confounding effects of $\beta$ blockers. Circulation 76 [Suppl IV]: IV-531 (Abstract)

24. Haffner SM, Mykkänen L, Stern MP, Paidi M, Howard BV (1994) Greater effect of diabetes on LDL size in women than in men. Diabetes Care 17: 1164-1171

25. Feingold KR, Grunfeld C, Coerrier W, Krauss RM (1992) LDL subclass phenotypes and triglyceride metabolism in non-insulin dependent diabetes. Arterioscler Thromb 12: 1496-1502

26. Temple RC, Clark P, Schneider A, Nagi DK, Yudkin JS, Hales CN (1989) Insulin deficiency in non-insulin dependent diabetes. Lancet I: 293-295

27. Temple RC, Clark P, Schneider A, Nagi DK, Yudkin JS, Hales CN (1990) Radioimmunoassay may overestimate insulin in non-insulin dependent diabetics. Clin Endocrinol 32: $689-693$
28. Ward WK, LaCova EC, Paquette TL, Beard JC, Wallum BJ, Porte D (1987) Disproportionate elevation of immunoreactive proinsulin in type 2 (non-insulin-dependent) diabetes mellitus and in experimental insulin resistance. Diabetologia 30: 698-702

29. Porte D (1991) Banting Lecture 1990. $\beta$ cells in type II diabetes mellitus. Diabetes 40: 166-180

30. Yoshioka N, Kuzuya T, Matsuda A, Taniguchi M, Iwamato Y (1988) Serum proinsulin levels at fasting and after oral glucose load in patients with type 2 (non-insulin-dependent) diabetes mellitus. Diabetologia 31: 355-360

31. Saad MF, Kahn SE, Nelson RG et al. (1990) Disproportionately elevated proinsulin in Pima Indians with non-insulin dependent diabetes mellitus. J Clin Endocrinol Metab 70: $1247-1253$

32. Davies MJ, Metcalfe J, Gray IP, Day JL, Hales CN (1993) Insulin deficiency rather than hyperinsulinaemia in newly diagnosed type II diabetes mellitus. Diabetic Med 10: 305312

33. Reaven GM, Chen YDI, Hollenbeck CB, Hseuh WH, Ostrega D, Polonsky KS (1993) Plasma insulin, C-peptide, and proinsulin concentrations in obese and non-obese individuals with varying degrees of glucose tolerance. J Clin Endocrinol Metab 76: 4448

34. Davies M, Rayman G, Gray IP, Day JL, Hales CN (1993) Insulin deficiency and increased plasma concentrations of intact and 32/33 split proinsulin in subjects with impaired glucose tolerance. Diab Med 10: 313-320

35. Nagi DK, Hendra TJ, Ryle AJ et al. (1990) The relationship of concentrations of insulin, intact proinsulin, and 32-33 split proinsulin with cardiovascular risk factors in type 2 (non-insulin-dependent) diabetic subjects. Diabetologia 33: 532-537

36. Haffner SM, Mykkänen L, Stern MP, Valdez RA, Heisserman JA, Bowsher RR (1993) Relationship of proinsulin and insulin to cardiovascular risk factors in non-diabetic subjects. Diabetes 42: 1297-1302

37. Mykkänen L, Rönnemaa M, Laakso M (1994) Low insulin sensitivity is associated with a clustering of cardiovascular risk factors. Diabetes 43 [Suppl 1]: 152A (Abstract)

38. Hazuda HP, Comeaux PJ, Stern MP et al. (1986) A comparison of three indicators for identifying Mexican Americans in epidemiologic research: methodological findings from the San Antonio Heart Study. Am J Epidemiol 123: 96-112

39. Stern MP, Rosenthal M, Haffner SM, Hazuda HP, Franco LJ (1984) Sex difference in the effects of sociocultural status on diabetes and cardiovascular risk factors in Mexican Americans: the San Antonio Heart Study. Am J Epidemiol 120: 834-851

40. Haffner SM, Stern MP, Hazuda HP, Pugh JA, Patterson JK (1986) Hyperinsulinemia in a population at high risk for non-insulin dependent diabetes mellitus. $N$ Engl J Med 315: $220-224$

41. Haffner SM, Hazuda HP, Mitchell BD, Patterson JK, Stern MP (1991) Increased incidence of type II diabetes mellitus in Mexican Americans. Diabetes Care 14: 102-108

42. Bowsher RR, Wolny JD, Frank BH (1992) A rapid and sensitive immunoassay for the measurement of proinsulin in human serum. Diabetes 41: 1084-1090

43. World Health Organization Expert Committee (1985) Diabetes mellitus. WHO Technical Report, Series No. 727. Report of a WHO Study Group, World Health Organization, Geneva

44. Haffner SM, Stern MP, Hazuda HP, Pugh JA, Patterson JK, Malina R (1980) Upper body and centralized adiposity in Mexican Americans and non-Hispanic whites: relationship 
to body mass index and other behavioral and demographic variables. Int J Obesity 10: 493-502

45. Hypertension detection and follow-up program cooperative group (1976) The hypertension detection and followup program. Prev Med 5: 207-215

46. Joint national committee on detection, evaluation and treatment of high blood pressure (1993) The fifth report of the joint national committee on detection, evaluation and treatment of high blood pressure (JNC V). Arch Intern Med 153: 154-183

47. Summary of the second report of the national cholesterol education program (NCEP) expert panel on detection, evaluation and treatment of high blood cholesterol (adult treatment panel II) (1993) Expert panel on detection, evaluation and treatment of high blood cholesterol. JAMA 209: 3015-3023

48. Haffner SM, Mykkänen L, Valdez RA et al. (1994) Disproportionately increased proinsulin levels are associated with the insulin resistance syndrome. J Clin Endocrinol Metab 79: $1806-1810$
49. Hollenbeck CB, Chen N, Chen YDI, Reaven GM (1984) Relationship between plasma insulin response to oral glucose and insulin stimulated glucose utilization in normal subjects. Diabetes 33: 460-463

50. Mykkänen L, Haffner SM, Rönnemaa T, Bergman R, Leino A, Laakso M (1994) Is there any difference in the association of plasma insulin levels and insulin sensitivity with serum lipids and lipoproteins? Metabolism 43: 599-603

51. Hunt SC, Wu LL, Hopkins PN et al. (1988) Apolipoproteins, low density lipoprotein subfraction and insulin associations with familial combined hyperlipidemia: study of Utah patients with familial dyslipidaemic hypertension. Arteriosclerosis 9: 335-344

52. Austin MA, Mykkänen L, Kuusisto J et al. (1994) Small, dense low density lipoprotein (LPL) and elevated triglyceride (TG) prospectively predict non-insulin dependent diabetes mellitus (NIDDM) in the elderly. Circulation 40 [Part 2]: I460 (Abstract) 